\title{
Pain and pain relief with intrauterine device insertion
}

\section{Rebecca H Allen}

Associate Professor of Obstetrics and Gynecology, Department of Obstetrics and Gynecology, Women \& Infants Hospital of Rhode Island, The Warren Alpert Medical School of Brown University, Providence, RI, USA

\section{Correspondence to}

Dr Rebecca H Allen, Department of Obstetrics and Gynecology, Women \& Infants Hospital of Rhode Island, The Warren Alpert Medical School of Brown University, 101 Dudley Street, Providence, RI 02905, USA; rhallen@wihri.org

Received 23 August 2016 Accepted 1 September 2016

\section{CLinked}

- http://dx.doi.org/10.1136/ jfprhc-2016-101446

\section{CrossMark}

To cite: Allen RH. J Fam Plann Reprod Health Care 2016;42:239-240.
In this journal issue, Speedie and colleagues $^{1}$ examine whether the type of stabilising forceps (single-toothed tenaculum vs atraumatic forceps) applied to the cervix during intrauterine device (IUD) insertion influences the pain perceived among women who have had a vaginal delivery. They randomised 100 parous women and found that mean pain scores at the time of forceps application on a $0-10 \mathrm{~cm}$ visual analogue scale (VAS) were $1.5 \pm 1.8$ for the single-toothed tenaculum and 1.2 \pm 1.6 for the atraumatic (Littlewoods) forceps $(p=0.52)$. As expected, pain scores for IUD insertion itself were low among this group of women $(3.3 \pm 2.1$, single-toothed tenaculum vs $2.7 \pm 2.2$, atraumatic forceps, $p=0.10$ ). This finding is similar to a randomised controlled trial performed in the USA comparing single-toothed and atraumatic tenaculum types among 80 women undergoing IUD insertion, approximately half of whom had experienced a vaginal delivery. ${ }^{2}$

Intrauterine contraceptives are recommended as a first-line option for women of all ages by medical organisations due to their high efficacy and satisfaction rates. ${ }^{3}$ Providers have sought ways to make the insertion procedure more comfortable for women, given that some are deterred from this method due to fear of pain. The type of tenaculum used during IUD insertion seems to be joining other interventions for reducing pain that have been found in a recent Cochrane systematic review to have little effect or to be ineffective, depending on the specific patient group in which they are used. ${ }^{4}$ These include oral nonsteroidal anti-inflammatory drugs (NSAIDs), some topical lidocaine agents, and misoprostol for cervical ripening. So, how can we counsel women and help them through the IUD insertion process?

First, we know that women who are nulligravid, nulliparous or remote from their last delivery may experience more pain with IUD insertion. ${ }^{5}$ The type of previous delivery matters, with the vaginal route, not abdominal, being protective against pain with intrauterine procedures. While populations differ according to the study location, on average, women who have had a vaginal delivery, especially recently, have mild discomfort with insertion as described by Speedie et al. ${ }^{1}$ Women who are nulliparous, have had only Caesarean deliveries, or are approaching the menopause tend to have more discomfort, in the range 5-6 on a $0-$ $10 \mathrm{~cm}$ VAS. A minority of women will report severe levels of pain (i.e. a score of $7+)$. Second, the experience of pain is influenced by multiple factors and the level of pre-procedure anxiety and anticipated pain contributes significantly. ${ }^{5}$

Given these dynamics, a multimodal approach to reducing discomfort is necessary with any office gynaecological procedure. Such approaches were reviewed in this journal in 2014. ${ }^{6}$ Women should be counselled on what to expect during the insertion process, and having an assistant who can sit with the patient and distract her with conversation is also helpful, the so called 'vocal local' or 'verbocaine'. A heating pad is another useful technique to reduce discomfort, provide distraction, and let the woman know that her comfort is a priority. Providers should use their clinical judgement regarding additional pharmacologic pain control options according to individual patient characteristics and be prepared to offer them. If additional pain control is needed, the best option most providers have access to is injected paracervical or intracervical anaesthesia. A paracervical block with $20 \mathrm{ml}$ buffered $1 \%$ lidocaine, including injection at the tenaculum site, will provide some relief and acts immediately. Other lidocaine formulations that have been shown to be effective are $10 \%$ lidocaine spray and $2.5 \%$ lidocaine $/ 2.5 \%$ prilocaine cream; however, these need to be applied 37 minutes prior to the procedure. ${ }^{4}$ In addition, NSAIDs prior to the procedure will at least decrease uterine cramping after insertion, with naproxen and intramuscular 
ketorolac being two proven options. Further research in this area is always welcome, and emerging techniques under study include self-administered topical lidocaine agents placed vaginally $30-60$ minutes prior to the procedure to allow for full absorption and onset of action, as well as inhaled nitrous oxide/oxygen.

Competing interests The author has served on an advisory board for Bayer and Actavis which manufacture intrauterine devices.

Provenance and peer review Commissioned; internally peer reviewed.

\section{REFERENCES}

1 Speedie JMM, Mansour D, Landy R, et al. A randomised trial comparing pain and ease of use of two different stabilising forceps for insertion of intrauterine contraception. J Fam Plann Reprod Health Care 2016;42:241-6.
2 Doty N, MacIsaac L. Effect of an atraumatic vulsellum versus a single-tooth tenaculum on pain perception during intrauterine device insertion: a randomized controlled trial. Contraception 2015;92:567-571.

3 Faculty of Sexual \& Reproductive Healthcare. Intrauterine Contraception. 2015. https://www.fsrh.org/standards-andguidance/documents/ceuguidanceintrauterinecontraception/ [accessed 27 August 2016].

4 Lopez LM, Bernholc A, Zeng Y, et al. Interventions for pain with intrauterine device insertion. Cochrane Database Syst Rev 2015; 7:CD007373.

5 Ireland LD, Allen RH. Pain management for gynecologic procedures in the office. Obstet Gynecol Surv 2016;71: 89-98.

6 Bahamondes L, Mansour D, Fiala C, et al. Practical advice for avoidance of pain associated with insertion of intrauterine contraceptives. J Fam Plann Reprod Health Care 2014;40:54-60.

\section{Anne Szarewski Journal Memorial Award - Extended Eligibility Criteria}

The Journal of Family Planning and Reproductive Health Care has established an award to commemorate the life of Anne Szarewski, our Editor-in-Chief until 2013. Anne was an inspiring editor, a great sexual and reproductive healthcare doctor and a pioneering researcher in the prevention of cervical cancer.

The award will be made annually for a period of 5 years from June 2015. In addition to publication of the winning article in the journal (subject to satisfactory peer review), the winner will be offered the opportunity to present their work at one of the FSRH conferences during the year following the award, and will receive a complimentary registration for that conference.

Entries for the award should take the form of a single-author article, suitable for publication in the journal, on new initiatives or improvements in clinical practice. In response to previous submissions, the eligibility criteria have been extended/made more inclusive. The author must be a healthcare practitioner working in the area of sexual and reproductive healthcare or genitourinary medicine. Priority in judging will be given to excellent work by junior or recently qualified practitioners, or those for whom sexual health is not their main specialty.

Full details of the award can be found on the journal (http://jfprhc.bmj.com) and FSRH (https://www.fsrh. org/about-us/fsrh-scholarships-and-awards) websites. 